\title{
Volatile antimicrobials from Muscodor albus, a novel endophytic fungus
}

\author{
Gary A. Strobel, Emilie Dirkse, Joe Sears and Chris Markworth \\ Author for correspondence: Gary A. Strobel. Tel: +1 406994 5148. Fax: +1 4069947600. \\ e-mail: uplgs@montana.edu
}

Department of Plant Sciences ${ }^{1}$, and Department of Chemistry and Biochemistry2, Montana State University, Bozeman, MT 59717, USA

\begin{abstract}
Muscodor albus is a recently described endophytic fungus obtained from small limbs of Cinnamomum zeylanicum (cinnamon tree). This xylariaceaous fungus effectively inhibits and kills certain other fungi, and bacteria, by virtue of a mixture of volatile compounds that it produces. The majority of these compounds were identified by gas chromatography/mass spectrometry and then made into an artificial mixture that mimicked the antibiotic effects of the mixture of volatile compounds given off by the fungus. Each of the five classes of volatile compounds produced by the fungus (alcohols, esters, ketones, acids and lipids) had some inhibitory effect against the test fungi and bacteria, but none was lethal. However, collectively they acted synergistically to kill a broad range of plant- and human-pathogenic fungi and bacteria. The most effective class of inhibitory compounds was the esters, of which 1-butanol, 3-methyl-, acetate was the most active biologically. This report describes the ecological implications and potential practical benefits of the 'mycofumigation' effects of M. albus.
\end{abstract}

Keywords: endophyte, organic volatiles, pathogens, esters, aldehydes

\section{INTRODUCTION}

A conservative estimate of the number of fungi on our planet is 1.5 million (Hawksworth \& Rossman, 1987). However, the number of species described is only in the range of 70000-100000 (Hawksworth \& Rossman, 1987). One of the major niches to be explored for novel fungi and their products is the diminishing rainforests of the world. Besides expanding the world's mycological collections and learning more about microbial biodiversity, an alternative compelling reason for seeking out these unique microbes is the prospect that they may offer promising new biological systems for solving major problems in medicine, agriculture and commerce.

While exploring the rainforests of Central America we discovered a novel endophytic fungus, Muscodor albus (Woropong et al., 2001) and here we report on the production of volatile compounds by this filamentous fungus that are are both inhibitory and, for the most part, lethal to a broad range of pathogenic fungi and bacteria. Many fungal species are known to emit low concentrations of gaseous substances, especially ones that have distinctive obnoxious odours, and this has prompted appropriate chemical analyses of the fungal volatiles (Bjurman \& Kristensson, 1992). Some of these volatile substances are common to many fungi, whereas others seem to be unique for one species (Schnurer et al.,
1999; Rapior et al., 2000). Particularly relevant to this report are the observations of Dennis \& Webster (1971), who noted that certain Trichoderma spp. produced volatile antibiotics. These compounds inhibited the growth of such test fungi as Rhizoctonia solani, Pythium ultimum and Fusarium oxysporum. No lethality to any of the test fungi was reported by these authors and comprehensive chemical analyses of the volatile components of the fungal cultures were not performed, although acetaldehyde was suggested as one of the volatiles. Thus, in spite of some attention having been given to the volatile compounds of fungal cultures over the years, to our knowledge no lethal mixtures of volatile antimicrobials produced by fungi have been reported. However, here we show the separation and identification of volatile compounds from M. albus and a successful mimicry of their inhibitory activity with compounds obtained from synthetic and commercial sources. We also present in vivo data illustrating the practical implications for the use of the volatiles of this fungus in biological control measures as a mycofumigant.

\section{METHODS}

Culturing and storing $\boldsymbol{M}$. albus. The culture of M. albus used in this study was obtained as an endophyte from small limbs of Cinnamomum zeylanicum located in the Lancetilla Bot- 


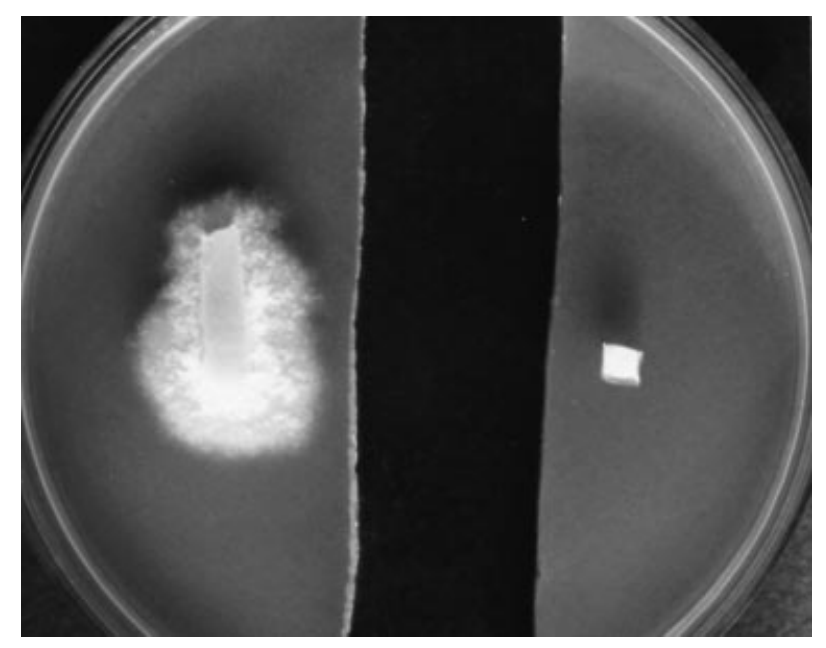

Fig. 1. A Petri plate $(9 \mathrm{~cm})$ illustrating the geometry of the bioassay system. An $M$. albus mycelial colony (2 weeks old) is on one side of the plate, a central agar strip has been removed, and the opposite side of the plate contains a small agar block supporting a test microbe.

anical Garden near La Ceiba, Honduras. Because plant materials being handled in the laboratory are infested with microscopic phytophagous mites, we placed all Petri plates containing water agar and the internal tissues of the ethanoltreated cinnamon tree stems into a plastic box in order to preclude invasion of the agar plates by these mites. After a few days, most plant tissues had sported fungal growth, but only one endophytic fungus was still alive. It seemed that this lone fungus had produced volatiles that had 'mycofumigated' the entire environment of the plastic container. The procedures used to isolate this organism have been described previously and include a thorough exposure of the external tissues to $70 \%$ ethanol prior to placement of the carefully excised internal tissues on water agar (Woropong et al., 2001). M. albus, a sterile xylariaceous fungus, has been taxonomically treated primarily on the basis of its $18 \mathrm{~S}$ rDNA sequences and their relatedness, but not identity, to other fungi in this group (Woropong et al., 2001). The fungus could best be stored after growth on sterile filter paper strips placed on the surface of plates of potato dextrose agar (PDA), subsequently removed, dried in a laminar flow hood, and the strips placed at $-70^{\circ} \mathrm{C}$. The fungus, under these conditions, remained viable for over 1 year. The fungus was also stored by placing its mycelium, on plugs of PDA, in sterile distilled water at $4{ }^{\circ} \mathrm{C}$. It remained viable for over 4 years.

Test fungi and bacteria. All plant-pathogenic fungi used in the bioassay system were obtained from Dr Don Mathre of the Montana State University Department of Plant Sciences. Candida albicans, and all bacterial cultures, were supplied by Dr Jim Cutler and Dr Mike Franklin, respectively, both of the Montana State University Department of Microbiology. All fungi and bacteria were grown on PDA at $23^{\circ} \mathrm{C}$.

Bioassay for volatile antimicrobials. A relatively simple bioassay system was devised that allows only for volatiles being the caustive agents for any microbial inhibition being examined. An agar strip $2.5 \mathrm{~cm}$ wide was completely removed from the mid-portion of a Petri plate of PDA. Then, M. albus was inoculated and grown on one side of the plate for varying time periods prior to testing. The test fungus or bacterium was placed on to the agar half-moon strip on the opposite side of the plate. Individual fungi were inoculated on the test side of the plate on a $3 \mathrm{~mm} \times 3 \mathrm{~mm} \times 3 \mathrm{~mm}$ plug of agar (Fig. 1). Bacteria and Candida albicans were simply streaked $(1.5 \mathrm{~cm}$ long streak) on to the PDA on the test side of the plate. Each bacterium and fungus was tested when it was producing fresh growth. The removal of a strip of agar from the mid-portion of the plate precluded the diffusion of any inhibitory soluble compounds emanating from $M$. albus to the fungi or bacteria being tested. The plate was wrapped with two layers of Parafilm and incubated at $23{ }^{\circ} \mathrm{C}$. The growth of the test organisms was visually judged on the basis of any new microbial density appearing on the area of the agar that had been inoculated. Eventually, the linear growth of the filamentous fungi (as measured from the edge of the agar inoculum plugs) and the viability of each test fungus and bacterium were evaluated. The latter was done by either removing the agar plug containing the test fungus and placing it on to a PDA Petri plate, or restreaking the test bacterium or yeast from the original test streak made on the test side of the plate. Appropriate control experiments were conducted in which the test fungus or bacterium was subjected to the same procedures minus $M$. albus on the test side of the Petri plate; in each case, normal growth and viability of each organism was noted. It should be noted that while PDA is not an ideal medium for the bacteria and human-pathogenic fungi used in this study, it did satisfactorily support the growth of these organisms. Its use, while adequately supporting the growth of M. albus, also obviated the need to pour other agar into the other half of the Petri plate to support the growth of the test fungus or bacterium.

Quantitiative and qualitative analyses of $\boldsymbol{M}$. albus volatiles. A method was devised to analyse the gases in the air space above the $M$. albus mycelium growing in Petri plates. First, the use of a solid-phase micro-extraction syringe (Supelco) was shown to be a convenient method for trapping the fungal volatiles. The fibre material was 50/30 divinylbenzene/ carburen on polydimethylsiloxane on a stable flex fibre. The syringe was placed through a small hole drilled in the side of the Petri plate and exposed to the vapour phase for $45 \mathrm{~min}$. The syringe was then inserted into a gas chromatograph (Hewlett Packard 5890 series II Plus) equipped with a massselective detector. A $30 \mathrm{~m} \times 0.25 \mathrm{~mm}$ ID ZB Wax capillary column with a film thickness of $0.50 \mathrm{~mm}$ was used for the separation of the volatiles. The column was temperature programmed as follows: $25^{\circ} \mathrm{C}$ for $2 \mathrm{~min}$, then increasing to $220^{\circ} \mathrm{C}$ at $5^{\circ} \mathrm{C} \mathrm{min}^{-1}$. The carrier gas was helium (UltraHigh Purity; local distributor) and the initial column head pressure was $50 \mathrm{kPa}$. The helium pressure was ramped with the temperature ramp of the oven to maintain a constant carrier gas flow velocity during the course of the separation. Prior to trapping the volatiles, the fibre was conditioned at $240{ }^{\circ} \mathrm{C}$ for 20 min under a flow of helium. A 30 s injection time was used to introduce the sample fibre into the gas chromatograph. The gas chromatograph was interfaced to a VG 70E-HF doublefocusing magnetic mass spectrometer operating at a mass resolution of 1500 . The mass spectrum was scanned at a rate of 0.50 s per mass decade over a mass range of 35-360 a.m.u. Data acquisition and data processing were performed on the VG SIOS/OPUS interface and software package. Initial identification of the unknown compounds produced by $M$. albus was made through library comparison using the NIST database on the mass spectrometer.

Comparable analyses were conducted on Petri plates containing only PDA, and the compounds obtained therefrom, mostly styrene, were subtracted from the analyses done on 
plates containg the fungus. Final identification of 20 of 28 compounds was done by comparison with authentic standards using the GC/MS methods described above. However, the eight remaining compounds have only been tentatively identified on the basis of the NIST database information; these were not included in any of the bioassays that employed artifical mixtures of $M$. albus compounds.

As a first approximation, the quantitive analysis of each compound found in the M. albus culture headspace was based on its relative peak area obtained after GC/MS analysis. These values were used to prepare artifical atmospheres of the $M$. albus gases in the relative proportions that they occur in culture.

Sourcing of fungal volatile compounds. The majority of the commercially available compounds produced by M. albus were obtained from Aldrich; however, valencene was obtained from Fluka. Synthetic bulnesene was a generous gift of Dr Clayton Heathcock of the Department of Chemistry, University of California Berkeley (Heathcock \& Ratcliffe, 1971). However, most of the major compounds (esters) found in the $M$. albus volatiles that were unavailable commercially or otherwise were synthesized by standard organic synthetic methods using the acylation methods of Hoefle et al. (1978) as follows.

Propanoic acid, 2-methyl, 3-methylbutyl ester. Isobutyryl chloride $(2 \mathrm{ml}, 19.1 \mathrm{mmol})$ was slowly added to a $0{ }^{\circ} \mathrm{C}$ solution of isoamyl alcohol ( $1 \mathrm{ml}, 9.5 \mathrm{mmol})$, 4-dimethylaminopyridine (583 $\mathrm{mg}, 4.8 \mathrm{mmol})$ and pyridine $(0.85 \mathrm{ml}, 10.5 \mathrm{mmol})$ in dichloromethane. A precipitate was evident $5 \mathrm{~min}$ after addition was complete. After stirring for $12 \mathrm{~h}$ under argon, the reaction was poured into $20 \mathrm{ml} 0.1 \mathrm{M} \mathrm{HCl}$. The layers were separated and the aqueous layer was extracted with $20 \mathrm{ml}$ methylene chloride. The organic layers were combined and washed with $10 \mathrm{ml}$ saturated aqueous ammonium chloride then $10 \mathrm{ml}$ saturated aqueous sodium bicarbonate. The organic layers were dried over magnesium sulfate, filtered, concentrated in vacuo, and purified by distillation through a $14 \mathrm{~mm}$ Vigreaux column (b.p. $60-62{ }^{\circ} \mathrm{C}, 25 \mathrm{~mm}$ ). The resulting clear, colourless oil was stirred over Amberlyst 15 to remove any remaining isobutyryl chloride. ${ }^{1} \mathrm{H}$ NMR (250 MHz, $\left.\mathrm{CDCl}_{3}\right) 4.09$ (t, 2H, J 6.7), $2.53(\mathrm{~m}, 1 \mathrm{H}), 1.68(\mathrm{~m}$, $1 \mathrm{H}), 1.52$ (q, 2H, J 6.5), 1.16 (d, 6H, J 7.0), 0.92 (d, 6H, J 6.5).

Propanoic acid, 2-methylethyl ester. Isobutyryl chloride $(2 \mathrm{ml}$, $19.1 \mathrm{mmol}$ ) was slowly added to a $0{ }^{\circ} \mathrm{C}$ solution of ethyl alcohol $(0.55 \mathrm{ml}, \quad 9.5 \mathrm{mmol}), \quad$ 4-dimethylaminopyridine $(583 \mathrm{mg}, 4.8 \mathrm{mmol})$ and pyridine $(0.85 \mathrm{ml}, 10.5 \mathrm{mmol})$ in dichloromethane. A precipitate was evident $5 \mathrm{~min}$ after addition was complete. After stirring for $12 \mathrm{~h}$ under argon, the reaction was poured into $20 \mathrm{ml} 0.1 \mathrm{M} \mathrm{HCl}$. The layers were separated and the aqueous layer was extracted with $20 \mathrm{ml}$ methylene chloride. The organic layers were combined and washed with $10 \mathrm{ml}$ saturated aqueous ammonium chloride then $10 \mathrm{ml}$ saturated aqueous sodium bicarbonate. The organic layers were dried over magnesium sulfate, filtered, concentrated in vacuo, and purified by distillation through a $14 \mathrm{~mm}$ Vigreaux column (b.p. $102^{\circ} \mathrm{C}$ ). ${ }^{1} \mathrm{H}$ NMR $(300 \mathrm{MHz}$, $\left.\mathrm{CDCl}_{3}\right) 4.12$ (q, 2H, J 7.2), 2.52 (m, 1H), 1.25 (t, 3H, J 6.9), $1.16(\mathrm{~d}, 6 \mathrm{H}, J 7.2)$.

1-Butanol, 3 methyl-, acetate. Under an atmosphere of argon, acetyl chloride $(6.5 \mathrm{ml}, 91.8 \mathrm{mmol})$ was added dropwise to a $0{ }^{\circ} \mathrm{C}$ solution of isoamyl alcohol $(5 \mathrm{ml}, 45.9 \mathrm{mmol}), N, N-$ dimethylpyridine $(2.8 \mathrm{~g}, 23 \mathrm{mmol})$ and anhydrous pyridine $(4.1 \mathrm{ml}, 50.5 \mathrm{~mol})$ in dichloromethane $(92 \mathrm{ml})$. The reaction mixture was poured into $100 \mathrm{ml} 0.1 \mathrm{M} \mathrm{HCl}$, and the resulting layers were separated. The organic layer was washed with $50 \mathrm{ml}$ saturated aqueous ammonium chloride then dried over magnesium sulfate. The organic layer was filtered and concentrated in vacuo to a clear oil, which was purified by distillation (bp $134-136{ }^{\circ} \mathrm{C}$ ) to give isoamyl acetate. ${ }^{1} \mathrm{H}$ NMR $\left(300 \mathrm{MHz}, \mathrm{CDCl}_{3}\right) 4.08$ (t, 2H, J 6.9), 2.03 (s, 3H), 1.68 (m, $1 \mathrm{H}), 1.51$ (q, 2H, J 6.9), 0.92 (d, 6H, J 6.6).

Determination of $\mathrm{IC}_{50}$ values and other data on microbe inhibition. The relative ability of the authenticated volatile M. albus compounds to inhibit and kill test organisms was measured. Test solutions were prepared by placing compounds in vials in the relative proportions that they occurred in the gas phase of $M$. albus cultures. The test mixture was placed in a presterilized microcup $(4 \times 6 \mathrm{~mm})$ located in the centre of a Petri plate containing PDA. When not in use, the mixture was stored at $0{ }^{\circ} \mathrm{C}$. The test organisms, freshly growing and excised on $3 \mathrm{~mm} \times 3 \mathrm{~mm} \times 3 \mathrm{~mm}$ agar blocks (at least three agar blocks per test fungus), were placed $2-3 \mathrm{~cm}$ from the microcup and the plate wrapped with two layers of Parafilm. Measurements of linear mycelial growth were made from the edge of the agar blocks to the edge of the colony after a given time period. However, in the case of bacteria and Candida albicans the organisms were streaked on the test side of the PDA plate and checked for new visible growth and viability by restreaking from the original area of the agar plate that had been inoculated. Appropriate controls were also set up in which no test solution was placed into the microcup. Tests on 3.2-90 $\mu \mathrm{l}$ of the artifical mixture per $50 \mathrm{ml}$ of air space above the PDA plate were done on three replicates in order to obtain $\mathrm{IC}_{50}$ data for each test organism. Individual classes of compounds were also tested in the relative amounts in which they occur at the optimum concentration of the entire mixture, which is $60 \mu \mathrm{l}$ of test mixture per $50 \mathrm{ml}$ of air space above the culture in a standard Petri plate. For instance, the esters represent $44 \%$ of the mixture of the identified volatiles and were tested at $26.4 \mu \mathrm{l}$ per $50 \mathrm{ml}$ air space; the same procedure was used for each of the other classes of compounds that were identified. Finally, each individual compound, especially among the esters, was tested at the concentration or relative percentage in which it occurs in $60 \mu \mathrm{l}$. Viability of the test microbes was checked by aseptically removing the small agar block, placing it on a PDA plate and observing growth after $1-3 \mathrm{~d}$.

Plant mycofumigation tests. Two 2-week-old cultures of $M$. albus were each used to expose, for $4 \mathrm{~d}, 25$ seeds of barley that had been naturally contaminated with the smut fungus Ustilago hordei. During this time the seed germinated. Plates containing only PDA were used as controls in which 25 infested seeds per plate were placed for $4 \mathrm{~d}$. Non-infested seeds were used as another control. The seeds of each treatment were placed in plastic greenhouse pots $(15 \mathrm{~cm}$ diameter $)$ with a standard soil mix and watered liberally every $2 \mathrm{~d}$ for 15 weeks. Eventually, the plants were harvested and the number of seedheads that were infested determined versus the number of uninfected seedheads.

\section{RESULTS AND DISCUSSION}

\section{Effects of $M$. albus volatiles on various fungi and bacteria}

Initially, we ascertained that M. albus growing on PDA has maximal lethality to fungi and bacteria when grown for $10-14 \mathrm{~d}$ at $23^{\circ} \mathrm{C}$. We then tested a wide range of freshly growing test fungi and bacteria in the standard 
Table 1. Effects of the volatile compounds of $M$. albus and an artificial mixture of $M$. albus compounds on a group of test fungi and bacteria

After exposure to $M$. albus gases, each test organism was evaluated for its growth and viability after removal from the gases. The artificial atmosphere consisted of the compounds identified after analysis of the M. albus gases (see text and Table 2). The growth of the test organisms in the artificial atmosphere was measured after exposure to the artificial mixture of compounds at 3.2-90 $\mu$ l per $50 \mathrm{ml}$ in order to obtain $\mathrm{IC}_{50}$ values (see text for details). The percentage growth relative to the control and viability were measured after exposure to $60 \mu \mathrm{l}$ per $50 \mathrm{ml}$. Viability was determined after the removal of the compounds at $3 \mathrm{~d}$. The results are means of three determinations $\pm \mathrm{sD}$.

\begin{tabular}{|c|c|c|c|c|c|}
\hline Test microbe & $\begin{array}{l}\text { Growth after } 2 \mathrm{~d} \\
\text { exposure to } \\
\text { M. albus (\% vs } \\
\text { control) }\end{array}$ & $\begin{array}{l}\text { Viability after } 3 \mathrm{~d} \\
\text { exposure to } \\
\text { M. albus culture }\end{array}$ & $\begin{array}{l}\mathrm{IC}_{50} \text { in artificial } \\
\text { atmosphere for } \\
2 \mathrm{~d}\left(\mu 1 \mathrm{ml}^{-1}\right)\end{array}$ & $\begin{array}{l}\text { Growth }(\mathrm{mm}) \text { in } \\
\text { artificial atmosphere } \\
\text { (\% vs control) }\end{array}$ & $\begin{array}{l}\text { Viability after } 3 \mathrm{~d} \\
\text { exposure to } \\
\text { artificial } \\
\text { atmosphere }\end{array}$ \\
\hline Pythium ultimum & 0 & Dead & $0.48 \pm 0.01$ & 0 & Dead \\
\hline Phytophthora cinnamomi & 0 & Dead & $0.29 \pm 0.06$ & 0 & Dead \\
\hline Rhizoctonia solani & 0 & Dead & $0.08 \pm 0.02$ & 0 & Dead \\
\hline Ustilago hordei & 0 & Dead & $0.31 \pm 0.09$ & 0 & Dead \\
\hline Stagnospora nodorum & 0 & Dead & $0.15 \pm 0$ & 0 & Dead \\
\hline Sclerotinia sclerotiorum & 0 & Dead & $0.17 \pm 0.05$ & 0 & Alive \\
\hline Aspergillus fumigatus & 0 & Dead & $0.41 \pm 0.05$ & 0 & Alive \\
\hline Fusarium solani & $19.4 \pm 0.28$ & Alive & $1.13 \pm 0.07$ & $42.0 \pm 2$ & Alive \\
\hline Verticillum dabliae & 0 & Dead & $0.3 \pm 0$ & 0 & Dead \\
\hline Cercospora beticola & $17.5 \pm 3.5$ & Alive & $0.12 \pm 0.15$ & $8 \pm 2$ & Alive \\
\hline Tapesia yallundae & 0 & Dead & $0.64 \pm 0$ & $\overline{0}$ & Dead \\
\hline Xylaria sp. & $25 \pm 0$ & Alive & $0.41 \pm 0.03$ & 0 & Alive \\
\hline Muscodor albus & $100 \pm 0$ & Alive & $0.6 \pm 0$ & $17.5 \pm 7.5$ & Alive \\
\hline Candida albicans & 0 & Dead & ND & trace & Alive \\
\hline Escherichia coli & 0 & Dead & ND & 0 & Dead \\
\hline Staphylococcus aureus & 0 & Dead & ND & 0 & Dead \\
\hline Micrococcus luteus & 0 & Dead & ND & 0 & Dead \\
\hline Bacillus subtilis & 0 & Alive & ND & 0 & Alive \\
\hline
\end{tabular}

ND, Not determined in this experiment.

bioassay. The test organisms were selected to include a broad taxonomic representation of major plant and human fungal pathogens as well as representative Grampositive and Gram-negative bacteria (Table 1). Most test organisms were completely inhibited, and in fact killed, after $1 \mathrm{~d}$ exposure to the $M$. albus gases, but some, such as Rhizoctonia solani, required at least $2 \mathrm{~d}$ exposure to be killed (data not shown). Therefore, a more inclusive time frame of $3 \mathrm{~d}$ was used as the exposure period for all test fungi and bacteria. However, a few microbes, including Fusarium solani and Cercospora beticola, were only partially inhibited after a $3 \mathrm{~d}$ exposure to $M$. albus (Table 1), and some were not killed even by longer exposure (not shown). Also, the volatiles of $M$. albus did not kill M. albus itself or its close relative Xylaria sp., although they did inhibit the growth of Xylaria sp. (Table 1). Thus, the fungal volatiles are biologically selective. The range of microorganisms affected by the volatiles of M. albus is impressive: representative oomycetes, basidiomycetes, ascomycetes, deuteromycetes, and Gram-negative and Gram-positive bacteria were each inhibited after exposure to the gases of this fungus. Some, however, while being inhibited were not killed, as with Bacillus subtilus
(Table 1). The fungal human pathogens Aspergillus fumigatus and Candida albicans were sensitive to $M$. albus volatiles and killed by them (Table 1).

\section{Chemical compositon of the volatiles}

In order to begin to understand the nature of the lethal and inhibitory effects of the volatile substances produced by $M$. albus on the suite of test microbes, it was necessary to chemically analyse the gas phase of this fungus in culture. The compounds were tentatively identified by initial GC/MS separation. They fell into several classes of chemical substances: esters, alcohols, acids, lipids and ketones were present in the mixture of a 2-week-old culture (Table 2). Comparable analyses were done on the gas phase above an uninoculated PDA Petri plate; several compounds, including such major components as styrene, methyl isobutyl ketone, naphthlene and butylated hydroxytoluene, were identified and subsequently subtracted from the analysis done on the Petri plate containing $M$. albus. Final identification of 20 out of 28 compounds was done by comparison with authentic standards that were synthesized, acquired from Aldrich or Fluka, or 
Table 2. GC/MS analysis of the volatile compounds produced by M. albus

Several minor peaks and the breakthrough peak were omitted from the total analysis since they represent only $1 \%$ of the total area. Compounds found in the control PDA plate are not included in this table. RT, retention time.

\begin{tabular}{|c|c|c|c|c|}
\hline $\begin{array}{c}\text { RT } \\
(\min : s)\end{array}$ & $\begin{array}{l}\text { Total area } \\
\quad(\%)\end{array}$ & $m / z$ & Possible compound & $M_{\mathrm{r}}$ \\
\hline $3: 45$ & 0.33 & 114 & Octane & 114 \\
\hline $4: 19$ & 0.93 & 58 & Acetone & 58 \\
\hline $4: 37$ & 0.68 & 74 & Acetic acid, methyl ester & 74 \\
\hline $5: 56$ & 7.63 & 88 & Acetic acid, ethyl ester & 88 \\
\hline $6: 51$ & 0.31 & 102 & Propanoic acid, 2-methyl, methyl ester & 102 \\
\hline $7: 16$ & 6.24 & $*$ & Ethanol & 46 \\
\hline $8: 03$ & 2.07 & 116 & Propanoic acid, 2-methylethyl ester & 116 \\
\hline $11: 45$ & 0.58 & $*$ & Propanoic acid, 2-methyl 2-methylpropyl ester & 144 \\
\hline $12: 05$ & 2.06 & 74 & Isobutyl alcohol & 74 \\
\hline $12: 50$ & 22.24 & $*$ & 1-Butanol, 3-methyl-, acetate & 130 \\
\hline $14: 57$ & 1.53 & $*$ & Propanoic acid, 2-methyl, 3-methylbutyl ester & 158 \\
\hline $15: 28$ & 22.99 & $*$ & 1-Butanol, 3-methyl- & 88 \\
\hline $16: 08$ & 0.29 & 138 & †Furan, 2-pentyl- & 138 \\
\hline $18: 53$ & 0.29 & 142 & †4-Nonanone & 142 \\
\hline $20: 38$ & 0.41 & 142 & 2-Nonanone & 142 \\
\hline $21: 07$ & 0.30 & 204 & $\begin{array}{l}\text { †Naphthalene, decahydro-4a-methyl-1-methylene-7- } \\
\text { (1-methylethylidene)-, (4aR-trans)- }\end{array}$ & 204 \\
\hline $22: 54$ & 1.51 & 204 & $\begin{array}{l}\text { †Azulene, 1,2,3,4,5,6,7,8-octahydro-1,4-dimethyl-7- } \\
\text { (1-methylethenyl)-, [1S-(1.alpha.,4.alpha.,7.alpha.)] }\end{array}$ & 204 \\
\hline $23: 16$ & 0.94 & 204 & †Cyclohexene, 4-(1,5-dimethyl-1,4-hexadienyl)-1-methyl- & 204 \\
\hline $25: 20$ & 3.63 & 204 & $\begin{array}{l}\text { †1H-3a,7-methanoazulene, 2,3,4,7,8,8a-hexahydro-3,6,8,8- } \\
\text { tetramethyl-, [3R-(3.alpha.,3a.beta.,7.beta.,8a.alpha.)] }\end{array}$ & 204 \\
\hline $25: 30$ & 6.08 & 88 & Propanoic acid, 2-methyl & 88 \\
\hline $26: 04$ & 0.48 & 204 & Caryophyllene & 204 \\
\hline $27: 55$ & 0.34 & 204 & $\begin{array}{l}\text { †Naphthalene, 1,2,4a,5,6,8a-hexahydro-4,7-dimethyl-1- } \\
\text { (1-methylethyl)-, [1R-(1.alpha.,4a.alpha.,8a.alpha.)] }\end{array}$ & 204 \\
\hline $28: 34$ & 0.36 & 204 & †Spiro[5.5]undec-2-ene, 3,7,7-trimethyl-11-methylene- & 204 \\
\hline $28: 50$ & 1.07 & 204 & $\begin{array}{l}\text { Azulene, 1,2,3,5,6,7,8, 8a-octahydro-1, 4-dimethyl-7- } \\
\text { (1-methylethyenyl)-, [1S-(1.alpha.,7.alpha.,8a.beta.)] } \\
\text { (common name: bulnesene) }\end{array}$ & 204 \\
\hline $28: 57$ & 3.24 & 204 & $\begin{array}{l}\text { Naphthalene, 1,2,3,5,6,7,8,8a-octahydro-1,8a-dimethyl-7- } \\
\text { (1-methylethenyl)-, [1R-(1.alpha.,7.beta.,8a.alpha.)] } \\
\text { (common name: valencene) }\end{array}$ & 204 \\
\hline $31: 12$ & 1.74 & $*$ & Acetic acid, 2-phenylethyl ester & 164 \\
\hline $33: 17$ & 1.06 & 122 & Phenylethyl alcohol & 122 \\
\hline $39: 00$ & 9.76 & 204 & †Unknown & 204 \\
\hline
\end{tabular}

*No molecular-ion peak was observed in the spectrum of either the standard compound or the compound undergoing the analysis.

†Denotes that a spectrum and retention time of this component were observed and the substance matched to the most likely compound in the NIST database, but the data have not been confirmed by use of an appropriate identical standard compound by either retention time or MS. These compounds were not placed in the artificial mixture in the bioassay.

obtained from those who did the original synthesis of them. The standards yielded identical retention times and mass spectra to the fungal products. However, the remaining eight compounds have only been tentatively identified on the basis of the NIST database information; these were not included in any of the bioassays. The most abundant compound, based on the total area of the
GC analysis, was 1-butanol, 3-methyl- followed by 1butanol, 3 methyl-, acetate and an unknown compound with a 39 min retention time (Table 2). Collectively, the esters constituted the greatest percentage of compounds present in the gas phase of the M. albus culture, followed by alcohols, acids and lipids and ketones, in that order (Table 2). 


\section{Artificial test mixtures of the $M$. albus volatiles}

An artificial mixture containing each of the positively identified compounds in the M. albus volatiles was prepared and tested. The amount of each compound placed into the mixture was based on its relative proportional content to all other positively identified compounds in the gas phase of the M. albus culture (Table 2), as determined by the electron ionization cross-section (percentage of the total area) of the compound obtained in the GC/MS analysis. Agar plugs containing freshly growing test fungi (or streaked bacteria and Candida albicans) were positioned $2-3 \mathrm{~cm}$ from the centre microcup. The microcups contained various amounts of the artificial mixture of $M$. albus volatiles. In this manner, it was possible to calculate the $\mathrm{IC}_{50}$ in $\mu \mathrm{l} \mathrm{ml} l^{-1}$ (the concentration in $\mu \mathrm{l}$ per $\mathrm{ml}$ of air space in the Petri plate required to produce a $50 \%$ reduction in microbe growth relative to an untreated control) (Table 1) for the filamentous fungi. However, the bacteria and C. albicans were evaluated only for their inhibition and viability after exposure to the fungus or the artifical atmosphere (Table 2).

The test rate that was the most effective per plate was 60 $\mu \mathrm{l}$ per $50 \mathrm{ml}$ air space $\left(1.2 \mu \mathrm{l} \mathrm{m}^{-1}\right)$. The general response of the test microbes to the artificial mixture of volatiles, in many respects, mimicked the effects of the M. albus atmosphere (Table 1). For instance, the two plantpathogenic oomycetes, Pythium ultimum and Phytophthora cinnamomi, responded identically to the artificial mixture as they did to the M. albus atmosphere (Table 1), being both inhibited and killed. The same was noted for the pathogenic basidiomycetes Ustilago hordei and Rhizoctonia solani. Likewise, the ascomyctes and fungi imperfecti, Stagnospora nodorum, Tapesia yallundae and Verticillum dabliae, also followed this pattern (Table 1). Just as important, however, was the response of certain test microbes such as Fusarium solani and Cercospora beticola. These two fungi were only inhibited, not killed, by $M$. albus gases, and in the artificial atmosphere they behaved in the same manner (Table 2). On the other hand, Xylaria sp. and M. albus are relatives, and while neither was killed by the artificial atmosphere, M. albus was about $83 \%$ inhibited in its growth and Xylaria sp. was completely inhibited (Table 1). This suggests that the antimicrobial volatiles of the fungus are not general biocides, but selective in the microbes they affect. The same results with the artificial test mixture as with the fungal volatiles were also noted with each of the bacteria tested (Table 2). However, notable exceptions to an ideal correlation were the human pathogens Candida albicans and Aspergillus fumigatus, and the plant pathogen Sclerotinia sclerotiorum (Table 2), in that they were only inhibited and not killed in the artificial atmosphere.

There appeared to be no relationship of the $\mathrm{IC}_{50}$ values of the artificial mixture for the test organisms to their resistance to being killed or inhibited by this atmosphere (Table 1). However, since some test organisms (e.g. C. albicans, S. sclerotiorum and A. fumigatus) were not killed in the artificial atmosphere but were killed by the M. albus atmosphere (Table 2), one might suspect that a key ingredient that kills cells in these cases is missing in the artificial test atmosphere. Only the chemically confirmed volatiles were placed into the artificial mixture and one or more of the non-confirmed compounds may be critical to making a perfect mimic of the results with the M. albus atmosphere. Furthermore, the method of administering the artificial atmosphere probably does not perfectly mimic that of the $M$. albus culture itself by providing a constant flow of volatiles to the test microbe, and this may be critical to the response of some microbes.

Since the artificial atmosphere did closely mimic the inhibitory and lethal activities of the $M$. albus atmosphere, we further evaluated the individual classes of compounds in the natural volatiles of M. albus in order to determine the relative biological activity of each. Each class of compounds, in the relative proportions that they occur, was tested at at the level of the percentages that they occur in the total $60 \mu \mathrm{l}$ per $50 \mathrm{ml}$ air space $\left(1.2 \mu \mathrm{ml}^{-1}\right)$ (Table 3). This was done with a selected group of seven test fungi. Each group of compounds possessed some inhibitory activity against the test organisms, but on a comparative basis the esters had more inhibitory activity than any other group of compounds (Table 3). Quite obviously, some microbes were more sensitive within and between chemical classes than others; for instance Pythium ultimum was highly sensitive to the alcohols while it showed little or no response to the ketones and lipids (Table 3 ). Indeed, the lipids and ketones were the least biologically active group of substances (Table 3). It should be noted that the majority of compounds omitted from the assay were tentatively identified as lipids and as such may not be substantial contributors to the bioactivity of the gas atmosphere of M. albus (Tables 1 and 3). Overall, these observations on the biological effectiveness of the individual classes of compounds warranted further study.

\section{Testing of individual volatiles}

Each compound in the class of esters was individually evaluated. When a comparable test on each ester was conducted according to the conditions in Table 3, 1butanol, 3-methyl-, acetate almost completely mimicked the results of all esters as in Table 3. It represented $62 \%$ of all of the identified combined esters and was therefore tested at the level of $0.32 \mu \mathrm{l} \mathrm{m} l^{-1}$. Only slight inhibitory bioactivity was displayed by propionic acid, 2-methyl, 3-methylbutyl ester and little or no activity was noted on the part of the other esters. Although the esters (including 1-butanol, 3 methyl-, acetate) had inhibitory activity in the bioassays, under no conditions in any test was death of any test fungus observed after the standard $3 \mathrm{~d}$ exposure period. This is a significant observation, since the test organisms died both in the complete artificial atmosphere and in the natural Petri plate atmosphere of M. albus. The result strongly suggests 
Table 3. Inhibitory influence of each class of volatile compounds

The compounds were tested for a $2 \mathrm{~d}$ exposure at the relative concentrations that they occur in $M$. albus at the optimum test concentration of $60 \mu \mathrm{l}$ per $50 \mathrm{ml}$ air space $\left(1.2 \mu \mathrm{l} \mathrm{ml}^{-1}\right)$. Inhibition is expressed as the percentage of test fungus growth compared to a control not exposed to the test compounds. All measurements of mycelial growth compared to the untreated control were made as described in Table 1. None of the microbes was killed after a $3 \mathrm{~d}$ exposure to any of the artificial test mixtures given in this table. The results are means of three determinations \pm SD.

\begin{tabular}{|c|c|c|c|c|c|}
\hline \multirow[t]{2}{*}{ Test fungus } & \multicolumn{5}{|c|}{ Growth (\% of control) in presence of: } \\
\hline & $\begin{array}{c}\text { Alcohols } \\
\left(0.48 \mu \mathrm{ml}^{-1}\right)\end{array}$ & $\begin{array}{c}\text { Esters } \\
\left(0.53 \mu \mathrm{ml} \mathrm{m}^{-1}\right)\end{array}$ & 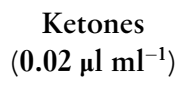 & $\begin{array}{c}\text { Acids } \\
\left(0.09 \mu 1 \mathrm{ml}^{-1}\right)\end{array}$ & $\begin{array}{c}\text { Lipids } \\
\left(0.08 \mu \mathrm{l} \mathrm{ml}^{-1}\right)\end{array}$ \\
\hline Pythium ultimum & $11.2 \pm 4$ & 0 & $67.5 \pm 7$ & $40.9 \pm 3$ & $75 \pm 0$ \\
\hline Rhizoctonia solani & $55 \pm 5$ & 0 & $67.5 \pm 7.5$ & $67.5 \pm 7.5$ & $40 \pm 0$ \\
\hline Tapesia yallundae & $35 \pm 15$ & 0 & $75 \pm 25$ & $100 \pm 0$ & $100 \pm 0$ \\
\hline Xylaria sp. & $75 \pm 25$ & 0 & $100 \pm 0$ & $100 \pm 0$ & $100 \pm 0$ \\
\hline Sclerotinia sclerotiorum & $29 \pm 3$ & $8.1 \pm 1.5$ & $20.6 \pm 12$ & $40 \pm 0$ & $78 \pm 2$ \\
\hline Cercospora beticola & $58 \pm 8$ & $5 \pm 5$ & $100 \pm 0$ & $83 \pm 17$ & $100 \pm 0$ \\
\hline Fusarium solani & $70 \pm 10$ & $55 \pm 5$ & $90 \pm 10$ & $80 \pm 20$ & $80 \pm 10$ \\
\hline
\end{tabular}

that an additive or synergistic mechanism is operational in the case of the M. albus volatiles. Thus, while each class of compounds possesses more or less inhibitory activity, a complete mixture of the ingredients is needed to bring about death of the test fungi and bacteria (Table 1).

\section{M. albus as a mycofumigant}

M. albus, in limited greenhouse experiments, was demonstrated to have potential practical uses. In controlled, replicated experiments, 25 barley seeds infested with Ustilago hordei (covered smut) were placed in each of two agar plates with the gases of M. albus for $4 \mathrm{~d}$ and then planted in test pots in the greenhouse. After 15 weeks the plants were harvested and evaluated for smut in the seed heads. There was $100 \%$ control of this disease in two groups of plants that had been exposed to $M$. albus gases and no sign of any inhibition or damage to the plants caused by the gas treatment. An identical number of control plants (untreated and $U$. hordei infested seed) had $50 \%$ and $41 \%$, respectively of infected seed heads. Also, as expected, uninfected seed yielded plants having no diseased grains. Similar experiments have been conducted with Muscodor albus in soil infested with soil pathogens such as Rhizoctonia solani, Pythium ultimum and Verticillum dabliae, with significant effective biological control of the soil-borne plant diseases incited by these pathogens (A. Stinson, B. Jacobsen, N. Zidack \& G. A. Strobel, unpublished results). These initial results are encouraging, given that in a few years the use of methyl bromide as a fumigant, widely used in agricultural soil treatment applications, will be banned for environmental and health reasons (Nelson, 1998). Conceivably, a mycofumigant may supplant the need for methyl bromide.

\section{M. albus and other gas producers as endophytes}

Generally, it is accepted that endophytic fungi may exist in their host plants in a range of biological associations from near-pathogenic to symbiotic (Bacon \& White, 2000). In the latter case, a number of endophytes have been discovered that make products that are extremely biologically active and selective against certain microbes that may be a potential threat to the host plant (Yang et al., 1994). In this manner the endophyte seems to have the potential to contribute to the benefit of the host by protecting it from a major biological threat - a plant pathogen. Some protective compounds recently isolated from endophytes are taxol, oocydin A, cryptocin, ambuic acid and jesterone (Stierle et al., 1993; Strobel et al., 1999; Li et al., 2000, 2001; Li \& Strobel, 2001). Each is active against a select group of pathogens and each is soluble in organic solvents. While this mechanism for the protection of the host plant may exist, with endophytes producing such compounds, it seems that no comparable situation involving a mixture of volatile lethal and inhibitory antimicrobials has been previously demonstrated. Given the current status of our understanding on the phenomenon of volatile antimicrobials, it appears that we have at least one operational hypothesis as to how M. albus may function in nature. That is, it may protect plant tissues against invading pathogens upon the release of a suite of inhibitory molecules.

M. albus is not the only lethal-gas-producing endophyte that we have been able to recover from plants. Recently, we have isolated two rainforest endophytes that are lethal to other microbes, by producing an entirely different suite of volatile compounds than M. albus. We have used M. albus as a selection tool to acquire these other lethal-gas producers. This can be done since 
organisms related to M. albus seem to be immune to the effects of these lethal volatiles (Table 1). Thus, it appears that the emission of gases from endophytic fungi that are lethal to other microbes is not a case strictly confined to M. albus in C. zeylanicum in Cental America, but it may be a common phenomenon in the life of all rainforests. This work again illustrates the importance of conserving the biodiversity in all of the world's ecosystems.

\section{ACKNOWLEDGEMENTS}

The authors appreciate financial support from the NSF, the USDA and the Montana Agricultural Experiment Station. Dr Eugene Ford provided invaluable assistance in isolating, observing and studying the original culture of M. albus. Other advice and help was provided by Ms Bryn Daisy, Dr Uvi Castillo and Dr J. Woropong.

\section{REFERENCES}

Bacon, C. W. \& White, J. F., Jr (2000). Microbial Endophytes. New York: Marcel Dekker.

Bjurman, J. \& Kristensson, J. (1992). Volatile production by Aspergillus versicolor as a possible cause of odor in houses affected by fungi. Mycopathologia 118, 173-178.

Dennis, C. \& Webster, J. (1971). Antagonistic properties of species-groups of Trichoderma. 11. Production of volatile antibiotics. Trans Br Mycol Soc 57, 41-48.

Hawksworth, D. C. \& Rossman, A. Y. (1987). Where are the undescribed fungi? Phytopathology 87, 888-891.

Heathcock, C. H. \& Ratcliffe, R. (1971). Stereoselective total synthesis of the guaiazulenic sesquiterpenoids $\alpha$-bulnesene and bulnesol. J Am Chem Soc 93, 1746-1757.

Hoefle, G., Steglich, W. \& Vorbrueggen, H. (1978). 4-Dialkyl aminopyridines as highly active acylation catalysts. Angew Chem Int Ed Engl 17, 569-583.
Li, J. Y. \& Strobel, G. A. (2001). Jesterone and hydroxy-jesterone antioomycete cyclohexenone epoxides from the endophytic fungus Pestalotiopsis jesteri. Phytochemistry 57, 261-265.

Li, J. Y., Strobel, G. A., Harper, J., Lobkovsky, E. \& Clardy, J. (2000). Cryptocin, a potent tetramic acid antimycotic from the endophytic fungus Cryptosporiopsis cf. quercina. Org Lett 2, 767-770.

Li, J. Y., Harper, J., Grant, D. M., Tombe, B. O., Bashyal, B., Hess, W. M. \& Strobel, G. A. (2001). Ambuic acid, a highly functionalized cyclohexenone with antifungal activity from Pestalotiopsis spp and Monochaetia sp. Phytochemistry 56, 463-468.

Nelson, P. V. (1998). Greenhouse Operation and Management, 5 th edn. New York: Prentice-Hall.

Rapior, S., Fons, F. \& Bessiere, J. (2000). The fenugreek odor of Lactarius helvius. Mycologia 92, 305-308.

Schnurer, J., Olsson, J. \& Borjesson, T. (1999). Fungal volatiles as indicators of food and feeds spoilage. Fungal Genet Biol 27, 209-217.

Stierle, A., Strobel, G. A. \& Stierle, D. (1993). Taxol and taxane production by Taxomyces andreanae, an endophytic fungus of Pacific yew. Science 260, 214-216.

Strobel, G. A., Li, J. Y., Sugawara, F., Koshino, H., Harper, J. \& Hess, W. M. (1999). Oocydin A, a chlorinated macrocyclic lactone with potent anti-oomycete activity from Serratia marcescens. Microbiology 145, 3557-3564.

Woropong, J., Strobel, G. A., Ford, E. J., Li, J. Y., Baird, G. \& Hess, W. M. (2001). Muscodor albus anam. nov., an endophyte from Cinnamomum zeylanicum. Mycotaxon 79, 67-79.

Yang, X., Strobel, G. A., Stierle, A., Hess, W. M., Lee, J. \& Clardy, J. (1994). A fungal endophyte-tree relationship; Phoma sp. in Taxus wallichiana. Plant Sci 102, 1-9.

Received 12 June 2001; revised 20 July 2001; accepted 30 July 2001. 